\title{
A Sala de Aula Invertida como Modelo Experimental de Formação Continuada: Concepções dos Professores Cursistas que Atuam no Ensino Médio
}

\author{
Ádila de Lima Ferreira ${ }^{1}$, Akynara Aglaé Rodrigues Santos da Silva Burlamaqui ${ }^{2}$ \\ ${ }^{1}$ Instituto Metrópole Digital - Universidade Federal do Rio Grande do Norte (UFRN) \\ Natal/RN
}

${ }^{2}$ Programa de Pós-Graduação em Inovação em Tecnologias Educacionais

\{adilaferreiral4@gmail.com, akynara@gmail.com\}

\begin{abstract}
This article is the result of the application of an experimental model of continuing teacher education based on the inverted classroom (SAI). The presented excerpt brings a comparative analysis of the experience, from the point of view of the theoretical references studied and the teachers' conceptions before the course and after, with emphasis on the contributions for the incorporation in the pedagogical practice. Fifteen (15) teachers who work in high school at a state public school participated in the training. The course was developed in a hybrid format, supported by SAI's own strategies, with a view to understanding and effective reflection of its use integrated with digital technologies. At the end of the training, the teachers were satisfied with the course proposal, intending to use the SAI in the classes of their subjects and suggested an expansion with a focus on deepening the active methodologies.
\end{abstract}

Resumo: O presente artigo é resultado da aplicação de um modelo experimental de formação continuada de professores baseado na sala de aula invertida (SAI). O recorte apresentado traz uma análise comparativa da experiência, sob o ponto de vista dos referenciais teóricos estudados e as concepções dos docentes antes do curso e depois, com ênfase nas contribuições para a incorporação na prática pedagógica. Participaram da formação quinze (15) professores que atuam no Ensino Médio de uma escola pública estadual. $O$ curso foi desenvolvido no formato híbrido, apoiado nas estratégias da própria SAI, com vistas a compreensão e reflexão efetiva do seu uso integrado às tecnologias digitais. Ao término da capacitação, os professores se mostraram satisfeitos com a proposta do curso, intencionados a utilizar a SAI nas aulas de suas disciplinas e sugeriram uma ampliação com foco no aprofundamento das metodologias ativas.

\section{Introdução}

O cenário de imersão na cultura digital há algum tempo vem revelando novas perspectivas para educação, principalmente por estar à disposição de um repertório amplo de recursos que podem ser explorados no processo de ensino e aprendizagem. $\mathrm{O}$ avanço na forma de produzir e disseminar o conhecimento reflete, de modo especial, na formação dos professores, que precisam assumir novas posturas frente ao uso das tecnologias, rompendo com a própria cultura de uma pedagogia tradicionalmente realizada. 
As Diretrizes de Políticas da Organização das Nações Unidas para a Educação, a Ciência e a Cultura (UNESCO) voltadas à Aprendizagem Móvel mostram que, "sem orientação e capacitação, os professores frequentemente utilizam a tecnologia para fazer coisas velhas de formas novas", ao invés de transformar e melhorar abordagens de ensino e aprendizagem [UNESCO 2014, p.33]". A formação permanente é um dos caminhos mais importantes para a construção de propostas eficazes através do aproveitamento significativo das possibilidades que as tecnologias digitais associadas ao uso de metodologias adequadas podem oferecer.

Esses aspectos ligados às inquietações pessoais e profissionais das pesquisadoras e as necessidades e expectativas apresentadas por um grupo de professores, resultaram neste trabalho científico sobre a inserção da sala de aula invertida (SAI) numa proposta de formação docente continuada. A escolha deu-se a partir da compreensão de sua pertinência enquanto metodologia ativa, que possibilita a inclusão de estratégias pedagógicas e ferramentas digitais e inverte a lógica tradicional de uma aula, estimulando a aprendizagem dinâmica do estudante e a mediação do professor.

O objetivo principal do estudo foi analisar a experiência deste modelo de formação continuada baseada na sala de aula invertida, com professores do Ensino Médio de uma escola pública estadual, localizada no município de Extremoz/RN. E como objetivos secundários, buscou-se realizar um levantamento das condições e necessidades reais para a implementação do experimento; elaborar e desenvolver a proposta de curso, tendo a SAI como conteúdo e metodologia; e avaliar as suas contribuições para o aperfeiçoamento de saberes e competências e incorporação na prática pedagógica.

Assim, o presente artigo trata-se de um recorte de pesquisa de mestrado, organizado em quatro partes: na primeira, se apresenta o referencial teórico das categorias bases do trabalho: formação continuada de professores à luz de Gatti e Barreto (2009), Imbernón (2011) e Libâneo (2011) e sala de aula invertida através da visão de Bergmann e Sams (2018), Valente (2014) e Bacich e Moran (2018). A segunda parte caracteriza a metodologia, que segue os paradigmas da pesquisa de natureza qualitativa e o método da pesquisa-ação conforme Thiollent (2011). A terceira consiste nas discussões e análises do experimento conforme a avaliação dos professores cursistas. E por fim, nas considerações finais, refletiu-se sobre todo o percurso da pesquisa, apontando contribuições, desafios e perspectivas.

\section{Formação Continuada de Professores}

Nos últimos anos a formação continuada de professores é tema de interesse nos debates sobre a qualidade da educação do país. A difusão de pesquisas no contexto acadêmico tem gerado diferentes propostas e alternativas de intensificação de ações voltadas para formação desses profissionais pelos sistemas educativos. Gatti e Barreto (2009) comentam que mesmo diante de alguns avanços nesses aspectos, os resultados escolares dos estudantes, em termos de desempenho, não têm se mostrado satisfatório no país.

Conforme Veiga, (2012, p. 15) “o processo de formação é multifacetado, plural, tem início e nunca tem fim”. Assim, a ideia de desenvolvimento profissional constante leva ao entendimento de que a formação continuada deve ser instrumento de reflexão teórica sobre a prática, de forma que possa promover a aquisição de novos saberes e competências profissionais que se traduza em aprimoramento significativo para o trabalho pedagógico dos professores. 
Outra visão que merece atenção é discutida por Imbernón (2010, p.09) sobre o tratamento dado ao processo de formação continuada: "não podemos separar a formação do contexto de trabalho, porque nos enganaríamos em nosso discurso. Ou seja, tudo que se explica não serve para todos e nem se aplica a todos os lugares". É essencial se pensar em um currículo de formações continuadas que consista no estudo de situações práticas reais, que apresentem aos professores soluções para as problemáticas atuais e locais do processo de ensino-aprendizagem.

Libâneo (2011) enfatiza a dificuldade das escolas em se organizarem para a efetivação de um contexto de trabalho formativo, resultando em pouco investimento no desenvolvimento de formação continuada de professores no seu interior. Esse é um dos aspectos que tem levado os professores a se interessarem menos pela autoformação, pelo crescimento nas dimensões pessoal e profissional. O desinteresse também se torna expressivo quando se busca a oferta de formações inadequadas, distanciada da realidade e que não apresentam aos docentes motivos para ressignificarem sua sala de aula.

Dadas as novas exigências, Imbernón (2011, p.51) “supõe que a formação permanente deve estender-se ao terreno das capacidades, habilidades e atitudes e que os valores e as concepções de cada professor e professora e da equipe como um todo devem ser questionados permanentemente". Portanto, é preciso ampliar as discussões sobre as políticas, planos e programas de formação continuada vigentes, pois os desafios são muitos, porém sem professores valorizados e continuamente qualificados fica difícil mudar a realidade educacional do país.

\section{Sala de Aula Invertida: uma metodologia ativa e didático-pedagógica}

A expansão do uso de tecnologias digitais de informação e comunicação (TDICs) estreita cada vez mais a distância entre as conexões em espaços físicos e virtuais. Os papeis de professores e alunos no processo de ensino-aprendizagem foram intensificados, sobretudo com a ampliação das noções de metodologias ativas, que ganham novos formatos e modalidades para a educação.

Além disso, as metodologias ativas apresentam diferentes combinações por meio de modelos híbridos, que contribuem para um redesenho de possibilidades educacionais para os aprendizes de hoje [Bacich e Moran 2018]. A sala de aula invertida (ou flipped classroom) é uma desses modelos, cuja a abordagem tem raízes no ensino híbrido (ou Blended Learning), que no contexto educacional se caracteriza de maneira inovadora ao combinar ensino online com sala de aula tradicional, buscando extrair o melhor desses dois segmentos.

A SAI foi descrita pelos professores Jonathan Bergmann e Aaron Sams, que trabalhavam em uma escola de Química denominada Woodland Park High School, no Colorado, Estados Unidos, em meados de 2007, que inquietos com as dificuldades de aprendizagem apresentadas pelos estudantes e com desenvolvimento das mesmas aulas todos os dias, passaram a buscar alternativas didáticas para o exercício de um ensino com melhores resultados. O conceito básico da metodologia consiste em: "o que tradicionalmente é feito em sala de aula, agora é executado em casa, e o que tradicionalmente é feito como trabalho de casa, agora é realizado em sala de aula" [Bergmann e Sams 2018, p.11]. Esse entendimento conceitual é ampliado por Valente (2014) quando diz que a SAI acontece da seguinte maneira: 
O conteúdo e as instruções são estudados online antes de o aluno frequentar a sala de aula, que agora passa a ser o local para trabalhar os conteúdos já estudados, realizando atividades práticas como resolução de problemas e projetos, discussão em grupo, laboratórios etc. [p.85]

A abordagem metodológica da SAI propõe uma mudança na função do professor, que passa de expositor de conteúdo para orientador de aprendizagem, fortalecendo a participação ativa dos estudantes com a oferta de atividades personalizadas, que valorizam sobretudo as diferentes formas de aprender, num contexto baseado na interação, colaboração e trabalho em equipe.

É importante destacar que a medida que as práticas com a SAI se intensificam, os alunos ganham autonomia para desenvolverem, com o auxílio do professor, os próprios materiais didáticos para estudo, possibilitando assim uma melhor interação com o conhecimento construído e desenvolvendo diferentes formas de expressão [Guimarães $e t$ al 2018]. É nesse sentido que vale a pena insistir na importância de conhecer diferentes meios de atuação da prática docente através da Sala de Aula Invertida.

\section{Metodologia: abordagem, métodos e materiais}

A abordagem qualitativa foi utilizada para a consolidação do presente estudo por ter um caráter exploratório e abarcar diferentes estratégias metodológicas, técnicas e instrumentos. Além de focar em "compreender as relações, as visões e o julgamento dos diferentes atores, sobre a intervenção na qual participam, entendendo que suas vivências e reações fazem parte da construção da intervenção e de seus resultados [Minayo; Assis e Souza 2010, p.82]". O método adotado foi a pesquisa-ação, caracterizada por Thiollent (2011), como:

A pesquisa-ação é um tipo de pesquisa com base empírica que é concebida e realizada em estreita associação com uma ação ou com a resolução de um problema coletivo e no qual os pesquisadores e participantes representativos da situação ou do problema estão envolvidos de modo cooperativo ou participativo [p.20].

Em conformidade com as etapas previstas numa pesquisa-ação foi necessário realizar algumas adaptações para que o processo de desenvolvimento da investigação fosse satisfatório. Dessa forma, as fases para a condução do trabalho foram: a teoria, a partir da construção do referencial teórico das categorias de estudo; fase exploratória para a compreensão da problemática; o planejamento e construção da proposta do curso de formação; implementação do modelo experimental de formação continuada baseada na SAI; estruturação dos dados coletados; avaliação dos resultados alcançados; e divulgação externa da pesquisa.

Para a avaliação dos resultados, visando o alcance dos objetivos propostos, optouse pela análise comparativa de dois aspectos: 1) os conhecimentos já adquiridos pelos sujeitos sobre o assunto investigado e as suas expectativas sobre a formação continuada; e 2) as concepções dos cursistas quanto às contribuições do curso para o aperfeiçoamento de saberes e competências e incorporação na prática pedagógica.

Para a coleta dos dados foi utilizado o instrumento questionário eletrônico, no Google Formulários, para diagnóstico do cenário investigado e posteriormente para avaliar a formação continuada. O primeiro questionário (Q1) estava composto por 14 questões, entre abertas e fechadas, abrangendo 04 dimensões: o perfil dos participantes; 
o uso das tecnologias digitais; o conhecimento sobre a SAI; e as expectativas sobre a formação continuada. Já o segundo questionário (Q2) estruturou-se por 06 questões, também abertas e fechadas, com enfoque na avaliação do curso. Aqui destacou-se algumas, consideradas com maior relevância para subsidiar a análise comparativa.

\subsection{Sujeitos da pesquisa, perfis e expectativas}

Inicialmente foram caracterizados os perfis dos participantes da pesquisa, nos quais 15 responderam ao Q1. Das questões 01 a 05 diagnosticou-se que são professores de diferentes áreas de conhecimentos (Linguagens, Matemática, Ciências da Natureza e Ciências Humanas), atuando no Ensino Médio de uma Escola Pública Estadual, localizada no município de Extremoz/RN. Desses, 11 são do sexo masculino e 04 feminino; 09 tem entre 31 e 40 anos de idade; 03 entre 40 e 50 anos; 02 entre 20 e 30 anos; e apenas 01 com mais de 50 anos. Quanto a formação acadêmica, 07 são especialistas; 05 têm apenas a graduação; e 03 são mestres. Referente ao tempo de atuação na educação, 07 tem entre 06 a 10 anos de docência; 05 entre 11 a 15 anos; e 03 entre 01 a 05 anos.

Na segunda dimensão do Q1, das questões 06 a 09 foi tratado sobre familiaridade e uso dos recursos tecnológicos pelos professores. No dia a dia, a maioria, 07 (46,5\%), responderam que usam o WhatsApp com maior regularidade, 03 (20\%) o Google Drive e $05(33,5 \%)$ outras ferramentas distintas. Também foi importante saber se costumam utilizar as tecnologias digitais no planejamento e execução de suas aulas, e 09 professores afirmaram que às vezes usam; 05 sempre utilizam; e 01 apontou que nunca utilizou, como mostra os percentuais do Gráfico 1.

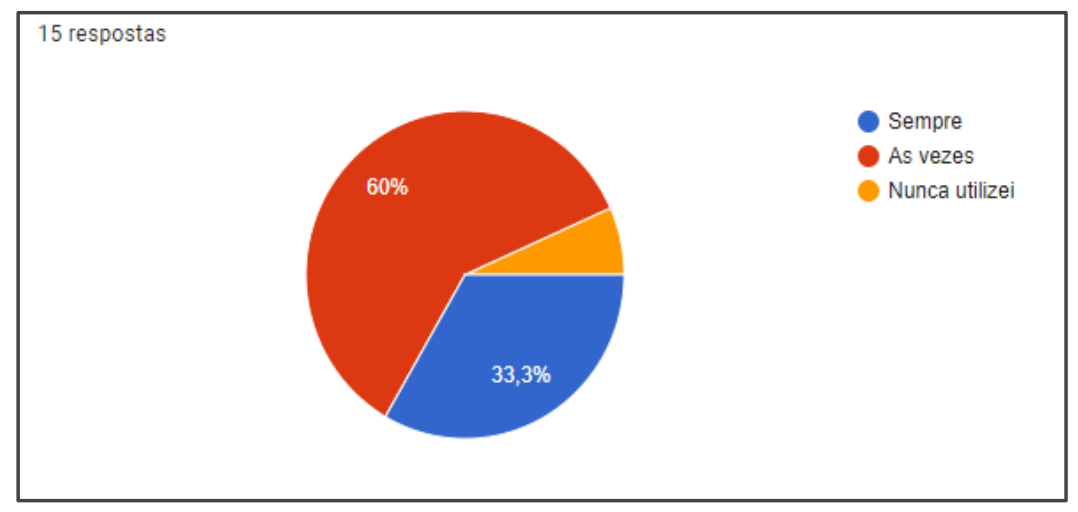

\section{Gráfico 1: Respostas da questão 08 do Q1 sobre o uso docente das tecnologias digitais no planejamento e execução das aulas.}

Nas questões 10 e 11, buscou-se entender sobre o conhecimento dos participantes referente ao método da SAI. Sobre o grau de saberes, as respostas foram as seguintes: 03 professores afirmaram que não conhecem; 06 sabem pouco; 05 tem um grau de entendimento moderado; e 01 tem bom conhecimento. Estas porcentagens estão delimitadas no Gráfico 2. 


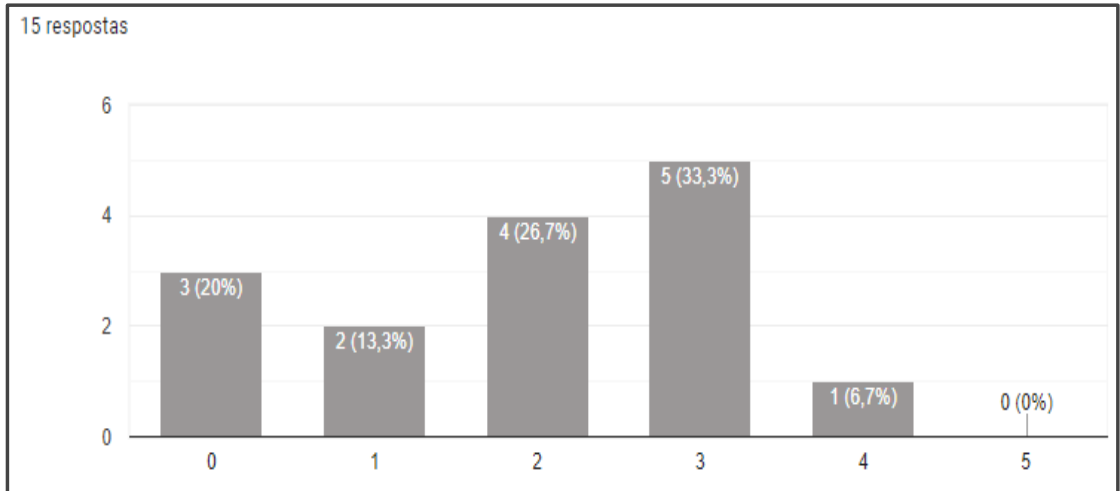

Gráfico 2: Respostas da questão 10 do Q1 sobre o grau de conhecimento dos participantes sobre a sala de aula invertida.

Aprofundando a compreensão sobre o assunto de investigação, na questão 11 foi perguntado aos participantes se já utilizaram a SAI e em que situação de ensino e aprendizagem da disciplina. Dentre as respostas, 09 (60\%) docentes nunca fizeram uso da metodologia e $06(40 \%)$ afirmaram já ter utilizado. Considerou-se para análise a seguinte prática apresentada por um dos participantes que confirmou fazer uso: "num tema de caráter cultural solicitei a apresentação por parte dos alunos sobre o tema, na sequência fiz uma abordagem de correção a partir do trabalho apresentado".

O método da SAI consiste em oferecer a informação básica do conteúdo antecipadamente em ambientes virtuais, com uso de diferentes recursos, e na sala de aula são desenvolvidas as atividades mais criativas e que necessitam de supervisão [Moran 2015]. Tomando como referência essa concepção, percebeu-se que não há uma correspondência significativa com a prática relatada pelo participante, portanto, ficou evidente a necessidade de aperfeiçoamento sobre a metodologia, com vistas a uma melhor compreensão para a construção de um fazer significativo por partes dos sujeitos.

Um último ponto analisado, foram às próprias expectativas e visões dos participantes quanto ao processo formativo. Na questão 12, 86,7\% (13) das respostas mostraram que a instituição escolar raramente oferece oportunidade de formação continuada. Na questão 13, destacou-se o interesse de $100 \%$ dos respondentes em participar deste curso. E na questão 14, referente ao que os docentes esperavam da formação, evidenciou-se um dos relatos escritos: "usar as ferramentas de tecnologias digitais para desenvolver aulas mais dinâmicas e interativas, como o intuito de fazer com que os alunos aprendam mais facilmente sobre determinado conteúdo".

Mediante a expectativa do participante, foi possível refletir que o acesso aos recursos tecnológicos e sua utilização meramente técnica não se constitui em inovação na a educação. "A pedagogia sempre deve induzir a tecnologia, nunca o oposto" [Bergmann e Sams 2018, p.18]. Por isso, as informações coletadas no Q1 de diagnóstico reforçaram a importância de fundamentar as ações do experimento com vistas a promover aquisição de formas inovadoras de ensinar, integrando metodologia e tecnologia, a reflexão do professor sobre o processo vivenciado e a prática crítica diante do saber instituído.

\subsection{Planejamento e implementação do curso de formação docente continuada}

O curso de formação continuada foi planejado e estruturado no formato híbrido, apoiado pelas estratégias da própria SAI, para que os professores cursistas refletissem e 
avaliassem essa abordagem através da vivência no próprio processo formativo. Os conteúdos básicos foram disponibilizados através do Google Sala de Aula, que é uma ferramenta virtual gratuita, simples e fácil de utilizar até pelo E-mail, que já faz parte do cotidiano dos docentes.

A realização do curso foi em dezembro de 2019, totalizando 40 horas, distribuídas em 04 semanas a partir de 04 módulos: 1) Apresentação do curso; 2) Conhecendo a Sala de Aula Invertida; 3) Ferramentas digitais potencializadoras da SAI; 4) Produção de Planos de aula interdisciplinares para utilizar a SAI.

Durante a aplicação, os participantes realizaram os estudos prévios dos materiais, de forma online e individualizada e nos encontros presenciais na escola, previstos em cada módulo, foi o momento de os cursistas dialogarem e refletirem sobre o conteúdo e aprimoramento da prática através da estratégia de oficinas pedagógicas. Candau (1999, p.11) diz que "as oficinas são espaços de construção coletiva de um saber, de análise da realidade, de confrontação e intercâmbio de experiências."

\section{Resultados e Discussões}

Os resultados deste estudo decorreram de uma análise comparativa dos saberes e competências docentes anteriores à aplicação da proposta de formação continuada, que integrou a SAI com diferentes ferramentas das tecnologias digitais, e o ponto de vista avaliativo destes professores quanto ao aperfeiçoamento durante o curso, que poderão ser incorporados à prática educativa.

A compreensão partiu dos dados coletados no segundo questionário aplicado na finalização do curso. Foi respondido por 14 participantes, tendo em vista que no decorrer da formação um transferiu-se da escola. As 06 questões trataram da avaliação do curso. $\mathrm{Na}$ questão 01 os respondentes avaliaram se os materiais didáticos e as oficinas práticas facilitaram a compreensão do assunto. 07 (50\%) consideraram excelente, $6(42,9 \%)$ bom e $1(7,1)$ satisfatório. No Q1 foi verificado que a maioria usava esporadicamente as tecnologias digitais no fazer pedagógico. Ao perguntar, na questão 2 do Q2, sobre o grau de contribuição da formação no aperfeiçoamento de suas habilidades para utilizar tais recursos, 07 afirmaram ter sido satisfatório, 05 muito bom e 02 excelente, sendo apresentado os percentuais no Gráfico 2.

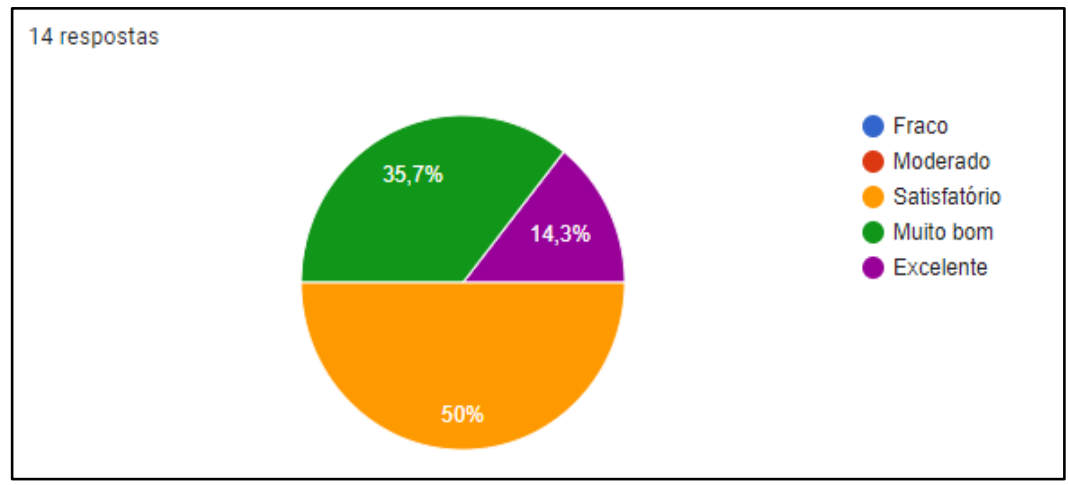

Gráfico 3: Respostas da questão 02 do Q2 sobre o grau de contribuição do curso no aperfeiçoamento para uso das tecnologias digitais. 
Ampliando essa questão, perguntou-se sobre a existência de dificuldades individuais nesse processo, e três participantes responderam: "poderia ser tido mais tempo para se apropriar das ferramentas". "Tive dificuldade no início porque desconhecia alguns recursos apresentados". "Minha dificuldade com algumas ferramentas foi porque não pude participar de todas as oficinas".

Entendeu-se com as percepções, que o uso das tecnologias ainda gera insegurança, principalmente pela falta de familiaridade com o uso efetivo na prática pedagógica. $\mathrm{O}$ aprofundamento com outras propostas de curso se faz necessário, bem como a busca pela autoformação, para que o docente deixe, de fato, a passividade diante dos recursos digitais, e passe a adquirir condições de eleger o que melhor se apresenta para preparar suas aulas de maneira significativa. "Um fator importante na capacitação profissional é a atitude do professor ao planejar sua tarefa docente não apenas como técnico infalível, mas como facilitador de aprendizagem, um prático reflexivo, capaz de provocar a cooperação e participação dos alunos" [Imbernón 2011, p.40].

Em relação a sala de aula invertida, foi percebido através do Q1, a necessidade de trabalhar os conceitos e a prática, visto que a maioria dos sujeitos pesquisados estavam na escala entre o não conhecer e o saber pouco sobre o método. Após o trajeto de estudo e vivências, na questão 4 do Q2, os participantes foram questionados sobre a intenção de utilizar a SAI integrada às tecnologias digitais na sua prática pedagógica e todos $(100 \%)$ informaram que sim.

Mediante o interesse dos professores em colocar em prática o que foi proposto na formação continuada, também foi analisado os saberes construídos em relação SAI, pois o diagnóstico do Q1 mostrava que os participantes ainda não faziam a correspondência adequada de suas estratégias. Assim, na questão 5 do Q2, os professores colocaram exemplos de como a SAI e as tecnologias digitais seriam incorporadas em uma aula de suas disciplinas.

Destacou-se as práticas descritas por três participantes: o primeiro apontou para "disponibilizar os conteúdos em ambiente virtual (textos, vídeos, imagens) para que o aluno tenha acesso para estudar em casa, e no espaço da sala de aula o aluno possa tirar dúvidas, interagir com os colegas e construir o conhecimento coletivamente". O segundo descreveu que "um exemplo prático, que pode ser facilmente implementado é a disponibilização prévia de vídeos preparatórios para a aplicação de atividades avaliativas". E o terceiro participante ponderou que "o conteúdo da aula poderia ser disponibilizado aos estudantes com alguma antecedência postado no Blog, WhatsApp ou Google Sala de Aula para que a interação professor/alunos fosse mais produtiva e significativa".

Foi observado a partir dos relatos de possíveis usos da SAI associada as ferramentas digitais, uma evolução na compreensão sobre o método, atingindo um nível esperado para planejar a incorporação na prática pedagógica. Bergmann e Sams (2018), idealizaram a SAI através da gravação de vídeos próprios e criação de documentos de apresentação de conteúdo das aulas (slides) com animação e voz. Mas deixaram claro que é preciso avaliar cuidadosamente qual é a ferramenta mais adequada para a utilização da metodologia através de cada realidade e de acordo com a proposta da tarefa a ser executada, para não correr o risco de prestar um desserviço pedagógico aos alunos. 
Finalizando o Q2, na questão 6, os respondentes foram solicitados a dissertar comentários gerais, e reflexões sobre o modelo de curso formativo, bem como dar sugestões, pensando em etapas futuras. Referente a proposição da formação, destacou-se a seguinte manifestação de um professor: "as tecnologias voltadas à educação maximizam o processo de ensino-aprendizagem e a formação continuada com as metodologias ativas fornecem ferramentas e ampliam as alternativas pedagógicas dos docentes”. Essa concepção se alinhou as perspectivas pretendidas, no sentido de provocar a reflexão crítica sobre a presença e utilização da tecnologia, não como mero instrumento técnico de apoio ao ensino, e sim mecanismo didático-pedagógico facilitador da aprendizagem, quando alinhada às metodologias inovadoras, como a SAI.

Considerou-se também algumas sugestões dadas pelos professores para futuras propostas de ampliação da formação continuada, como por exemplo: "um maior aprofundamento nas metodologias ativas". Almeida et al (2019) afirmam: "por mais que se discutam novas metodologias, novas propostas avaliativas e até novos recursos, a base teórica e pedagógica dessas iniciativas tem forte influência em nomes como Dewey, Vygotsky, Piaget, Freire e outros".

Com isso, compreende-se que as metodologias ativas já vinham sendo discutida em outros momentos e com total significância para o aprofundamento que se tem hoje. Mesmo com a intensa disseminação da importância de utilizar métodos inovadores e tornar o aluno protagonista de sua aprendizagem, o modelo de ensino tradicional continua permeando as práticas pedagógicas, deixando explícita a importância da formação do professor, como o principal agente de mudanças significativas na educação.

\section{Considerações Finais}

Por meio da análise comparativa dos dados e aporte teóricos apresentados neste artigo, concluiu-se preliminarmente, em virtude da pesquisa estar amplamente tratada no texto de dissertação de mestrado, que o curso aplicado apresentou contribuições ao aperfeiçoamento dos saberes profissionais, à medida que ficou explícita a compreensão dos participantes sobre os conhecimentos conceituais e didáticos da SAI aplicados à prática. Também foi satisfatório para o desenvolvimento da competência dos cursistas para a utilização de diferentes ferramentas digitais integradas pedagogicamente à SAI.

As concepções dos participantes antes e depois da formação, mostrou que a elaboração de capacitação docente precisa ser permeada através da identificação das demandas formativas existentes, para que venha a ser significativa e se constituir em mudanças na atuação dos profissionais. Refletir sobre essas ações executas na área, principalmente as potencialidades e limitações, torna possível estabelecer propostas de formação compatível com a realidade.

O modelo experimental realizado, suscita para as instituições escolares a valorização e manutenção de processos permanentes de capacitação para uso de tecnologias digitais com foco na inovação metodológica. Um curso de curta duração não é suficiente para sanar as lacunas oriundas da própria formação inicial destes profissionais, reforçando assim a importância da continuidade. Sendo fundamental o fortalecimento das relações didáticas do professor com as tecnologias digitais e as metodologias ativas, principalmente em uma sociedade informacional e imprevisível, que cada vez mais exige a ressignificação do exercício da docência. Além disso, as experiências adquiridas abriram o caminho para novos desdobramentos no mesmo 
contexto escolar, através da aplicação dos planos de aula interdisciplinares produzidos pelos professores no último módulo do curso, para a compreensão se o trabalho pedagógico com as estratégias da SAI, de fato, provoca melhorias efetivas na aprendizagem dos estudantes, comparada ao modelo tradicional de aula.

\section{Referências}

Almeida, Andrea C. A. et al. (2019) "Metodologias Ativas à Luz de Comenius: uma Experiência na Pós-Graduação". In: CONGRESSO SOBRE TECNOLOGIAS NA EDUCAÇÃO (CTRL+E), 4., Recife. Anais do IV Congresso sobre Tecnologias na Educação. Porto Alegre: Sociedade Brasileira de Computação, dec. p. 60-68. DOI: https://doi.org/10.5753/ctrle.2019.8876.

Bacich, Lilian e Moran, José. (2018) "Metodologias ativas para uma educação inovadora: uma abordagem teórico-prática”. Porto Alegre: Penso.

Bergmann, Jonathan e Sams, Aaron. (2016) "Sala de aula invertida: uma metodologia ativa de aprendizagem". Trad. Afonso Celso da Cunha Serra. Rio de Janeiro: LTC.

Candau, Vera M. (2018) "Oficinas pedagógicas de Direitos Humanos". Petrópolis: Vozes.

Gatti, Bernadete A. e Barreto, Elba S. de S. (2009) "Professores do Brasil: impasses e desafios". Brasília: UNESCO.

Guimarães, Felipe T. et al. (2018) "Métodos ativos de ensino aliados com tecnologia para a prática de ensino: um relato de experiência". VII Congresso Brasileiro de Informática na Educação (CBIE). Anais do XXIV Workshop de Informática na Escola. p. 333-342. Fortaleza: WIE, DOI: http://dx.doi.org/10.5753/cbie.wie.333.

Imbernón, Francisco. (2011) "Formação Docente e profissional: formar-se para a mudança e a incerteza". 9 ed. São Paulo: Cortez.

Libâneo, José C. (2011) "Adeus professor, Adeus Professora? Novas exigências educacionais e profissão docente”. 13 ed. São Paulo: Cortez.

Minayo, Maria C. de S., Assis, Simone G. e Souza, Edinilsa R. (2010) “Avaliação por triangulação de métodos: Abordagem de programas sociais. $3^{a}$ reimpressão". Rio de Janeiro: Editora Fiocruz.

Morán, J. (2015) Mudando a educação com metodologias ativas. In: Souza, C. A. de. e Morales, O. E. T. (Orgs.). "Convergências midiáticas, educação e cidadania: aproximações jovens”. Ponta Grossa, PR: Foca Foto-PROEX/UEPG, p.1533 .

Thiollent, Michel. (2011) "Metodologia da pesquisa-ação". 18. ed. São Paulo: Cortez.

Valente, José Armando. (2014) "Blended learning e as mudanças no ensino superior: a proposta da sala de aula invertida". Educar em Revista, Curitiba, n. 4, p. 79-97.

Veiga, Ilma P. A. (2012) Docência como atividade profissional. In: Veiga, Ilma P. A. e D’Ávila, Cristina (Org.). "Profissão docente: novos sentidos, novas perspectivas". Campinas: Papirus. 